\title{
Investigation of Hydrogen Production by using Zinc Coated Platinum Electrode in Phosphate Solutions
}

\author{
Mustafa K. Sangun ${ }^{\mathrm{a}}$, Guray Kilincceker ${ }^{\mathrm{b} *}$ \\ ${ }^{a}$ Hatay Mustafa Kemal University, Faculty of Sciences and Letters, Department of Chemistry, \\ Hatay, 31060, Turkey \\ ${ }^{b}$ Cukurova University, Faculty of Sciences and Letters, Department of Chemistry, \\ Balcall, Adana, 01330, Turkey \\ gkilinc@cu.edu.tr
}

Keywords: hydrogen production, zinc, covered platinum, electrolysis, dihydrogen phosphate. In this study, the hydrogen gas producing was investigated at $298 \mathrm{~K}$ with zinc coated platinum (Pt$\mathrm{Zn})$ electrode in $0.1 \mathrm{M} \mathrm{NaH}_{2} \mathrm{PO}_{4}$ solution $(\mathrm{pH}=12.3)$. Electrolysis, electrochemical impedance spectroscopy (EIS) and potentiodynamic polarization techniques were used for the production of hydrogen gas. Scanning electron microscopy (SEM), energy dispersive X-ray analysis (EDX) and Xray fluorescence (XRF) were used for the surface analysis of the electrodes. A practical electrocatalytic experiment was designed to examine of hydrogen production by using a $\mathrm{Zn}$ plated $\mathrm{Pt}$ electrode and the efficiency of the hydrogen gas increased by $66.66 \%$ on the surface of the zinc coated platinum electrode.

\section{Introduction}

Despite the fact that petroleum was used as the main energy source in the past century, the depletion of fossil fuels such as petroleum and coal has triggered investigations of the expected sustainable energy source $[1,2]$. Hydrogen is the energy carrier that meets the general characteristics of alternative energy sources such as multipurpose use, transport, energy density, environmental impact, and effective cost of hydrogen gas. Scientists interest to research and development of a wide range of technologies to produce hydrogen economically and in environmentally friendly ways [3, 4]. Hydrogen has an increasing interest as a fuel for the future, when considering the emission of greenhouse gases such as carbon dioxide and methane. In this case, the production of an environmentally friendly energy carrier, such as hydrogen, can play an important role in achieving sustainable energy $[5,6]$.

For producing of hydrogen, water electrolysis, natural gas reforming, coal gasification, thermo-chemical water electrolysis 
techniques have been used [7]. The simplest method to supply a high-purity hydrogen gas is the electrolysis of water. On the other hand, the over tensions of electrolysis system increase the cost of this method [8]. In order to overcome this disadvantage, suitable electrode and working environment are being investigated. $\mathrm{KOH}$ and/or $\mathrm{NaOH}$ solutions, which are usually used in fuel cells, are also used in electrolysis to produce a non-polluting method to supply of hydrogen production. Electrodes to be used in electrolysis should show low overvoltage and increasing the efficiency of hydrogen [9-11].

In this study, it is aimed to find an economical and practical electrocatalytic material to examination of hydrogen production by using a zinc plated electrode in an alkaline environment. In order to determination of electrocatalytic effect; electrolysis, potentiodynamic polarization and electrochemical impedance spectroscopy were used [12]. For production of hydrogen, $\mathrm{Ag}, \mathrm{Pd}$ and Pt-modified alkaline leached NiCoZn composite coatings were used on a copper substrate by electrochemical technique in base media [13]. Hydrogen capture and release process were observed voltametrically at the surface of platinum electrodes. A porous organic cage material is used to bind and release hydrogen when deposited directly onto a platinum electrode and immersed into aqueous electrolyte [14]. Compared to other existing methods, water electrolysis has the advantage of producing extremely pure hydrogen $(>99.9 \%)$, which is ideal for some high value-added processes such as electronic component manufacturing [15]. Some practical studies concerning the development of electrolyzes show that electrolysis of alkaline water is a feasible method for the production of hydrogen. To further enhance the efficiency of alkaline water electrolysis, research and development studies are urgently needed to develop a new electrocatalysts. Also, effective electrolyte additives to focus on the development of physical/chemical electrode modifications and appropriate management of gas bubble are required for the future trends on producing of hydrogen [16]. Alkaline water electrolysis is easy and simply method for hydrogen production and those systems were reviewed. Basically, the system needs to increase efficiency of producing hydrogen and also research needed advantages like energy consumption, cost and maintenances, durability, reliability and safety [17]. The use of phosphate species as a catalysts of water electrolysis for production of hydrogen gas has been reported [18]. Also, as a catalysts Pt was found the more effective and electroactive for the production of hydrogen gas. PtO could formed on the electrode surface and decreased the activity of electrode. Therefore, Zn was plated the Pt surface and that can have changed the electrode morphology of $\mathrm{Pt}$ with an increase the activity of the surface pores [19].

The aim of this study is to find an 
economical and practical electrocatalytic material for examination of hydrogen production by using a $\mathrm{Zn}$ plated Pt electrode in an alkaline environment such as sodium dihydrogen phosphate $\left(\mathrm{NaH}_{2} \mathrm{PO}_{4}\right)$. For this purposes, an experimental design was applied to increase producing of hydrogen gas.

\section{Experimental Part}

\section{Materials and Methods}

For this experiment, platinum plate $(10 \mathrm{~mm} \times 10 \mathrm{~mm} \times 0.1 \mathrm{~mm})$ is connected with a bare of copper wire which is coated with polyester. The coating was prepared using 30.02\% $\mathrm{ZnSO}_{4} .7 \mathrm{H}_{2} \mathrm{O}, 1 \% \mathrm{ZnCl}_{2} .6 \mathrm{H}_{2} \mathrm{O}, 1.25 \% \mathrm{H}_{3} \mathrm{BO}_{3}$. In anode, platinum coatings were carried out under room conditions by applying a fixed $-1.140 \mathrm{~V}$ potential and $2.00 \mathrm{mAcm}^{-2}$ currents to the electrolysis system for 60 seconds. The surface of the platinum electrode is coated with $\mathrm{Zn}$ at a thickness of $1.35 \mu \mathrm{m}$ (Thickness meter: ISOSCOPE FMP30).

The electrochemical behavior of the platinum and the zinc plated platinum is immersed in a $0.1 \quad \mathrm{M} \quad \mathrm{NaH}_{2} \mathrm{PO}_{4}$ solution $(\mathrm{pH}=12.3)$ at constant temperature $(298 \pm 0.1 \mathrm{~K})$. The $\mathrm{pH}$ values of the solutions were adjusted with $\mathrm{NaOH}$.

The impedance measurements were obtained by potentiokinetic three-electrode technique (Potentiostat: Type CHI660C). Impedance measurements were recorded at $1 \mathrm{mV}$ in the frequency range of $10^{5} \sim 10^{-3} \mathrm{~Hz}$. The measurements were made with mixed potential.
A field of $1 \mathrm{~cm}^{2}$ and $99.999 \%$ purity platinum was used as the counter electrode and a silversilver chloride electrode $(\mathrm{Ag} / \mathrm{AgCl}, 3.0 \mathrm{M} \mathrm{KCl})$ was used as the comparator electrode.

The working electrodes were plotted with the current-potential curves $(-1.8 \mathrm{~V})$ polarized in the cathodic direction at a rate of $0.001 \mathrm{Vs}^{-1}$ from the measured equilibrium potential against the silver-silver chloride electrode. The obtained current values were converted to current density by using Microsoft Excel program taking into account the electrode surface and semilogarithmic current-potential curves were obtained.

The cathodic polarization curves were obtained at a corrosion potential of $-1.8 \mathrm{~V}$ with a scan rate of $0.001 \mathrm{Vs}^{-1}$. Experimental dissociation voltages for each pair of electrodes were determined from the current-potential curves obtained from a DC source by increasing $0.1 \mathrm{~V}$ from $0.0 \mathrm{~V}$ up to $5.8 \mathrm{~V}$ for both $\mathrm{Pt} / \mathrm{Pt}$ and $\mathrm{Pt} / \mathrm{Pt}-\mathrm{Zn}$ system. The producing of hydrogen gas was collected in a burette filled with electrolyte solution and volume was determined by pressure correction.

The contact angle (CA) measurements were performed handling the Sessile Droplet the method with $4 \mu \mathrm{L}$ droplets of deionized water as the solvents by using a KSV Attension Theta Lite TL 101 Optical Tensiometer.

The surface morphologies of the electrodes were evaluated by a Scanning Electron Microscope (SEM) by JEOL JSM- 
5500LV. The SEM images were also taken using a Carl Zeiss Evo 40 SEM instrument at high vacuum and $10 \mathrm{kV}$ EHT. The chemical composition of the electrodes surface was investigated by energy dispersive X-ray spectrometer (EDX), a part of SEM device and $\mathrm{Pt} / \mathrm{Pt}-\mathrm{Zn}$ layer were determined by X-ray fluorescence (XRF) analysis, with an Oxford Instruments XMET5100 XRF.

\section{Results and Discussion}

Nyquist diagrams

Nyquist curves are obtained for various overvoltages where the hydrogen output for the working electrodes is achieved and the curves obtained at $0.250 \mathrm{~V}$ cathodic overvoltage are given in Fig. 1.

Nyquist curves were obtained by $\mathrm{AC}$ impedance technique, the distance between the lowest and highest frequencies (the obtained half-ellipse diameter) gives the polarization resistance in the system. The resistance values determined from the curves obtained at $0.250 \mathrm{~V}$ over voltages are given in Table 1. When Figure 1 and Table 1 are examined, it can be seen that the polarization resistance is decreased by coating the platinum surface with zinc. The resistance at bare electrode at $0.250 \mathrm{~V}$ cathodic overvoltage is $28183 \Omega$ while it is very low at $7000 \Omega$ on the Pt-Zn electrode. These values show that the Pt-Zn electrode is encountered with much lower resistance during the formation of hydrogen gas. Thus, Pt-Zn electrode was approved that the yield of hydrogen evaluation is increased comparing with Pt-Pt electrode.
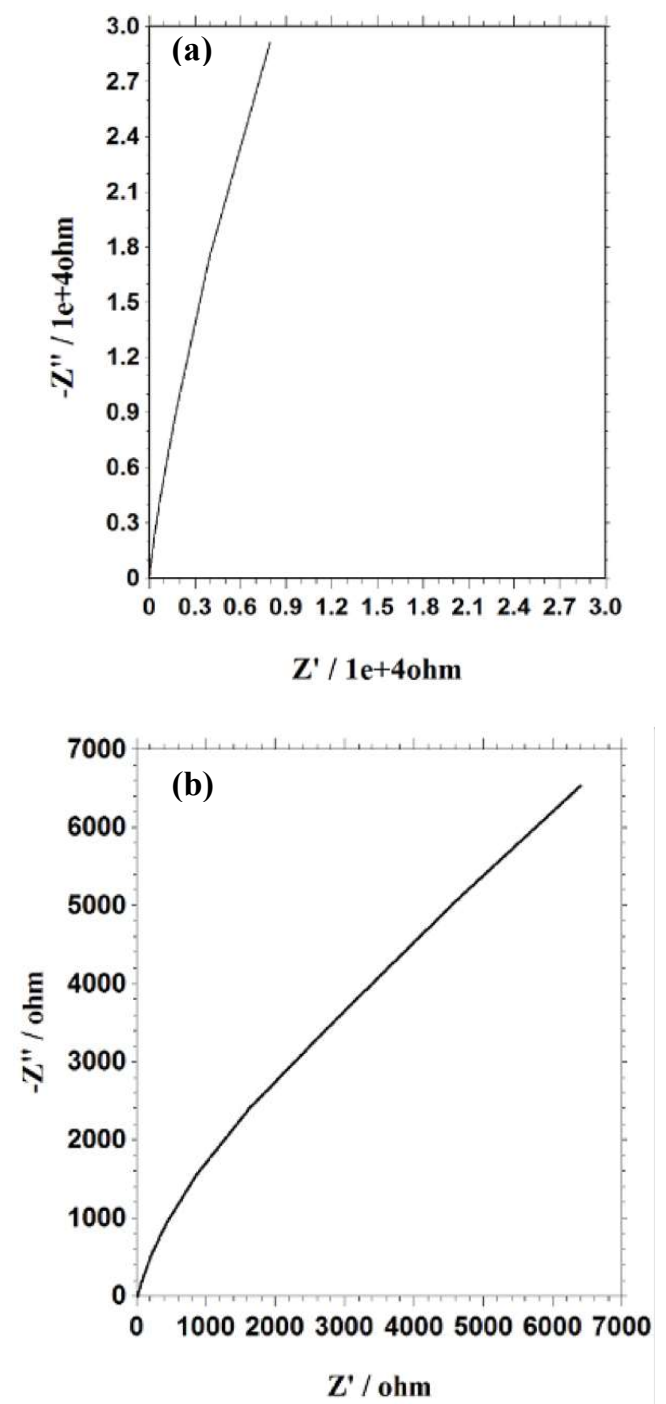

Figure 1. Nyquist curves obtained for $0.250 \mathrm{~V}$ cathodic overpotential working electrodes (a) $\mathrm{Pt} / \mathrm{Pt}$ and (b) $\mathrm{Pt} / \mathrm{Pt}$ $\mathrm{Zn}$.

Cathodic polarization curves

Cathodic polarization curves shows that hydrogen gas level was lower in the Pt-Zn electrode than in the Pt electrode. The current densities also proportional to the formation of hydrogen gas are shown to be higher in the Pt-Zn electrode compared to the same overvoltages and the corrosion potential is reported to be more negative (Fig 2, Table 1). 
Table 1. $R_{p}$ and $E_{\text {corr }}$ values determined from impedance measurements.

\begin{tabular}{cccc}
\hline \multirow{3}{*}{ Electrodes } & $\mathbf{E}_{\text {corr }}$ & $\mathbf{I}$ & \\
& $\mathbf{V}$ (vs. \\
& $\mathbf{A g} / \mathbf{A g C l})$ & $\left.\mathbf{A c m}^{-2}\right) \times \mathbf{1 0}^{-4}$ & $\mathbf{R}_{\mathbf{p}}$ (ohm) \\
\hline $\mathrm{Pt} / \mathrm{Pt}$ & 0.105 & 1.548 & 28183 \\
$\mathrm{Pt} / \mathrm{Pt}-\mathrm{Zn}$ & 0.187 & 5000 & 7000 \\
\hline
\end{tabular}
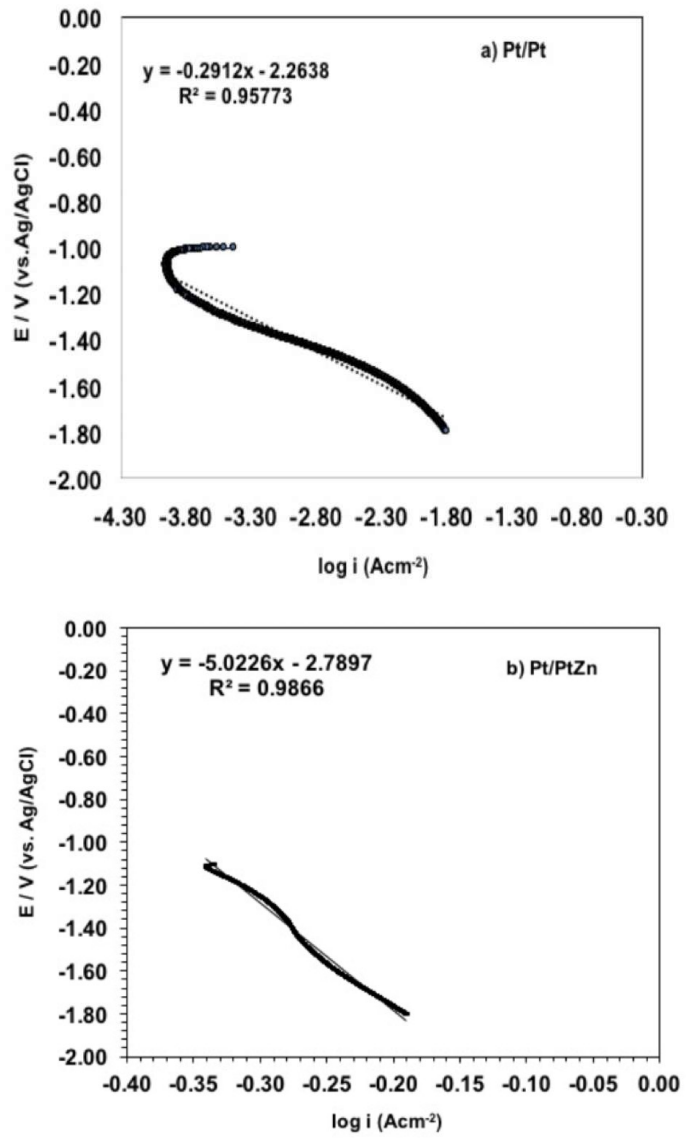

Figure 2. Cathodic polarization curves obtained for working electrodes (a) $\mathrm{Pt} / \mathrm{Pt}$ and (b) $\mathrm{Pt} / \mathrm{Pt}-\mathrm{Zn}$.

\section{Electrolysis}

The current potential curves for Pt and Pt-

$\mathrm{Zn}$ electrodes were used as cathodes are given in

Fig. 3a. As can be seen from Fig. 3a, the two curves are up to about $2.30 \mathrm{~V}$ resemble each other and almost no current flows through the systems. At $-1.80 \mathrm{~V}$ potential, there is a rapid increase in current densities due to hydrogen gas at the cathode and oxygen gas output at the anode. Pt electrode is compared with $\mathrm{Pt}-\mathrm{Zn}$ electrode the gas evolution at the Pt-Zn electrode starts earlier due to its low potential (Fig.3b.)
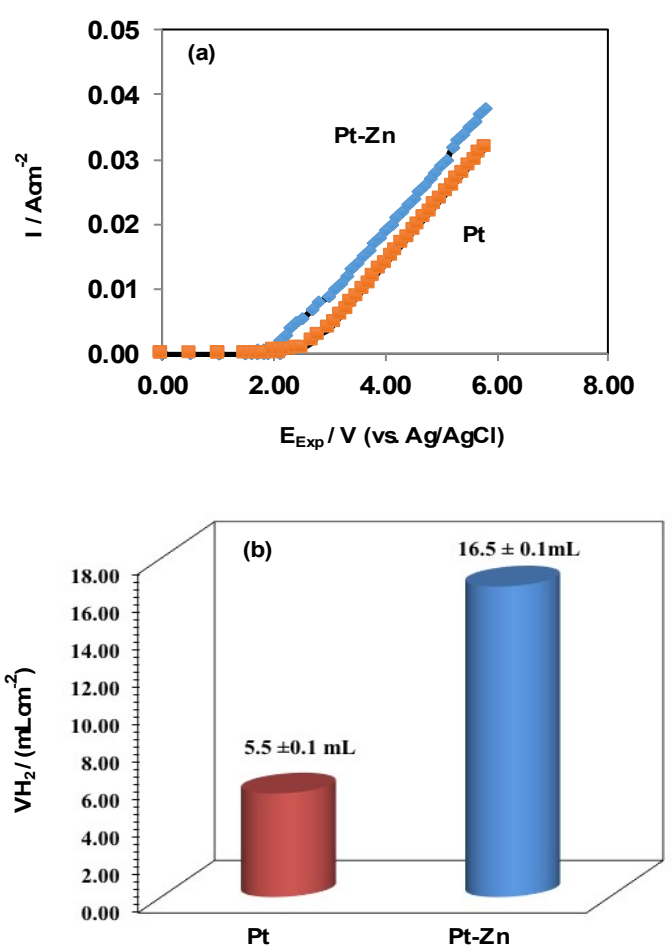

Figure 3. (a) The current-potential curves obtained by the two electrode techniques (b) The hydrogen gas volumes after 1 hour with the constant $5.8 \mathrm{~V}$ potential application.

Reactions in electrolytic system; during electrolysis of alkaline water, oxygen in the anode and hydrogen gas in the cathode are formed;

Anode: $4 \mathrm{OH}^{-} \rightarrow \mathrm{O}_{2(\mathrm{~g})}+2 \mathrm{H}_{2} \mathrm{O}+4 \mathrm{e}^{-} \quad \mathrm{E}_{\mathrm{A}}=$ $0.401-0.0592 \mathrm{pOH}$

$\mathrm{P}_{\mathrm{O}_{2}}=1.0 \mathrm{~atm}$

Cathode: $2 \mathrm{H}_{2} \mathrm{O}+4 \mathrm{e}^{-} \rightarrow 4 \mathrm{OH}^{-}+2 \mathrm{H}_{2(\mathrm{~g})} \mathrm{E}_{\mathrm{C}}=$ $-0.828-0.0592 \mathrm{pOH}$

$\mathrm{P}_{\mathrm{H}_{2}}=1.0 \mathrm{~atm}$

Total reaction; $2 \mathrm{H}_{2} \mathrm{O} \rightarrow \mathrm{O}_{2(\mathrm{~g})}+\mathrm{H}_{2(\mathrm{~g})}$

$E_{\text {Rev }}=1.23 \mathrm{~V}$ (vs. SHE)

$\eta_{T}=\eta_{A}+\eta_{C}$

$\eta_{T}=E_{E x p}-E_{\operatorname{Rev}}$

$E_{A}=1.23-0.059 p H+\eta_{A}$ 
$E_{C}=-0.059 \mathrm{pH}-\eta_{\mathrm{C}}$

$E_{E \times p}=E_{A}-E_{C}$

$E_{E x p}=1.23-0.059 \mathrm{pH}+\eta_{A}-\exists-0.059 \mathrm{pH}-\eta_{\mathrm{C}} E$

$E_{\text {Exp }}=1.23+\eta_{A}+\eta_{C}$

$\eta_{T}=E_{E \times p}-1.23$

$E \%=\frac{V_{H_{2}(P l P P-Z n)}-V_{H_{2}\left(P I P P_{t}\right)}}{V_{H_{2}}} x 100$

Table 2. Experimental dissociation tension, overvoltage and percentage of efficiency values in $0.1 \mathrm{M} \mathrm{NaH}_{2} \mathrm{PO}_{4}$ solution ( $\mathrm{pH}=12.3 ; 298 \mathrm{~K})$.

\begin{tabular}{cccc}
\hline Electrodes & $\begin{array}{c}\mathrm{E}_{E x p} \\
\text { V(vs. SHE) }\end{array}$ & $\begin{array}{c}\eta_{T} \\
\text { V(vs. SHE) }\end{array}$ & E\% \\
\hline $\mathrm{Pt} / \mathrm{Pt}$ & 2.10 & 0.87 & $66.66 \pm 0.01$ \\
$\mathrm{Pt} / \mathrm{Pt}-\mathrm{Zn}$ & 1.60 & 0.37 & \\
\hline
\end{tabular}

The reversible decomposition voltage of water is $1.23 \mathrm{~V}$ at $298 \mathrm{~K}$ [19]. The theoretically $1.23 \mathrm{~V}$ potential should be applied to the system in order to be able to produce hydrogen at the cathode and oxygen at the anode. However, the potential for overvoltage in the system should be higher than $1.23 \mathrm{~V}$.

The overvoltage $\left(\eta_{T}\right)$ values in the system are calculated by equation 11 and together with experimental dissociation voltages $\left(\mathrm{E}_{E x p}\right)$ in Figure $3 \mathrm{~b}$ and Table 2.

The percentage of hydrogen yield calculated by Equation 12 is given in table 2 . When the percentage of hydrogen yield is examined; it has been determined that the platinum surface is coated with zinc to increase the efficiency.

In the Table 2, when the Pt/Pt-Zn electrode is used as a cathode, the overvoltage in the electrolysis system is less than $\mathrm{Pt} / \mathrm{Pt}$ electrode. Hydrogen gas was occurred on the $\mathrm{Pt} / \mathrm{Pt}$ and $\mathrm{Pt} / \mathrm{Pt}-\mathrm{Zn}$ electrodes experimental dissociation voltages $\left(\mathrm{E}_{\text {Exp }}\right)$ are found as $2.10 \mathrm{~V}$ and $1.60 \mathrm{~V}$ respectively. After electrolysis $\mathrm{pH}$ changed 12.37 .

\section{Surface Analysis of Platinum and zinc-plated platinum by SEM, EDX and XRF}

The surface morphologies of the electrodes were evaluated and Pt/Pt-Zn layer were determined by a SEM, EDX and XRF analysis. The results of the EDX and XRF were proved that $\mathrm{Zn}$ was coated on the surface of electrode (Table 3 and Table 4).

In Figure $4 \mathrm{a}$ and $4 \mathrm{~b}$; The surface of the $\mathrm{Pt} / \mathrm{Pt}$ electrode and zinc coated Pt/Pt-Zn electrode were characterized by SEM (JEOL JSM-5500LV). The surface of the Pt/Pt electrode and zinc coated $\mathrm{Pt} / \mathrm{Pt}-\mathrm{Zn}$ electrode were also analyzed by EDX a part of SEM (Carl Zeiss Evo 40 SEM).

The EDX spectra of the coatings and the distribution of elements (elementary mapping) on the surfaces are shown in Figures $5 \mathrm{a}$ and $5 \mathrm{~b}$. The basic mapping of the layers clearly shows that $\mathrm{Zn}$ is evenly distributed over the strata. The results are proved that the porous surface of the $\mathrm{Pt} / \mathrm{Pt}-\mathrm{Zn}$ electrode is covered with a thin film layer of zinc. Film formation increases porosity on the electrode surface. In addition, the formation of the porous film layer has a decreasing polarization resistance (28183-7000 $\Omega$ ). This kinetic data supports the results of 
electrolysis and the overvoltage of Pt / Pt-Zn electrode according to $\mathrm{Pt} / \mathrm{Pt}$ decreases (Table 2). It can be clearly seen that, the porosity is increased and the hydrogen yield is increased due to the increase of the surface area of Pt / Pt-Zn.
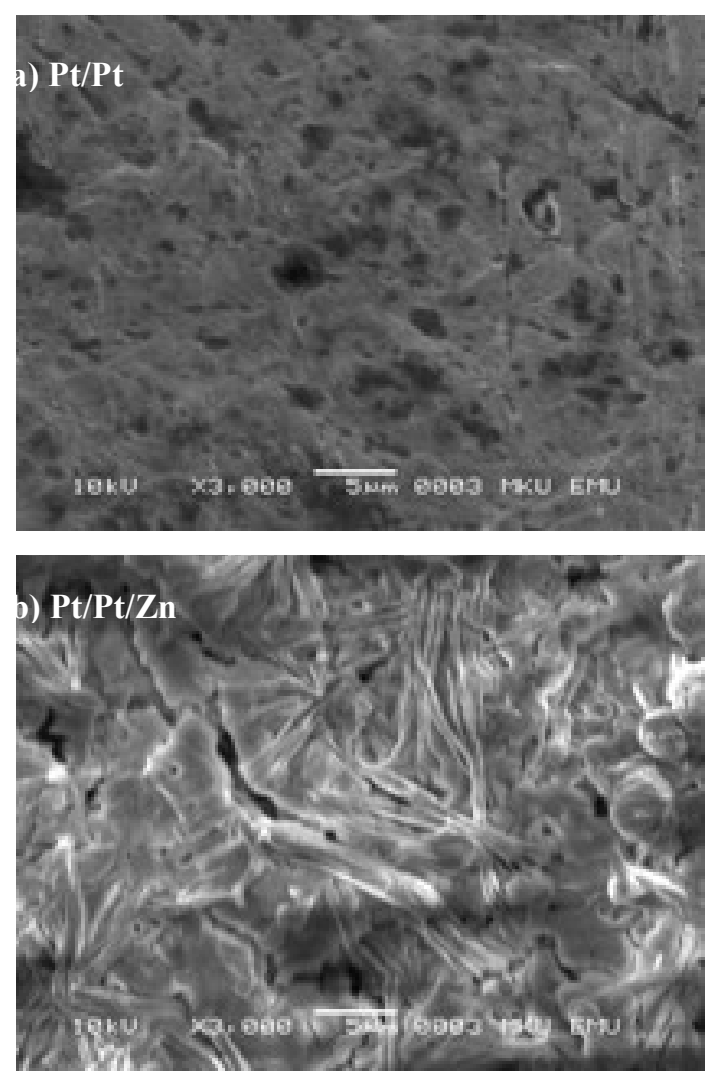

Figure 4. Surface analysis of Platinum and Zinc plated Platinum by SEM.

Table 3. The elemental analysis of the layers determined by $\operatorname{EDX}($ wt.\%).

\begin{tabular}{cccccc}
\hline $\begin{array}{c}\text { Working } \\
\text { Electrodes }\end{array}$ & Pt & Zn & O & S & Cl \\
\hline $\begin{array}{c}\mathrm{Pt} / \mathrm{Pt} \\
\mathrm{Pt} / \mathrm{Pt}-\mathrm{Zn}\end{array}$ & 95.05 & - & 4.95 & - & - \\
\hline
\end{tabular}
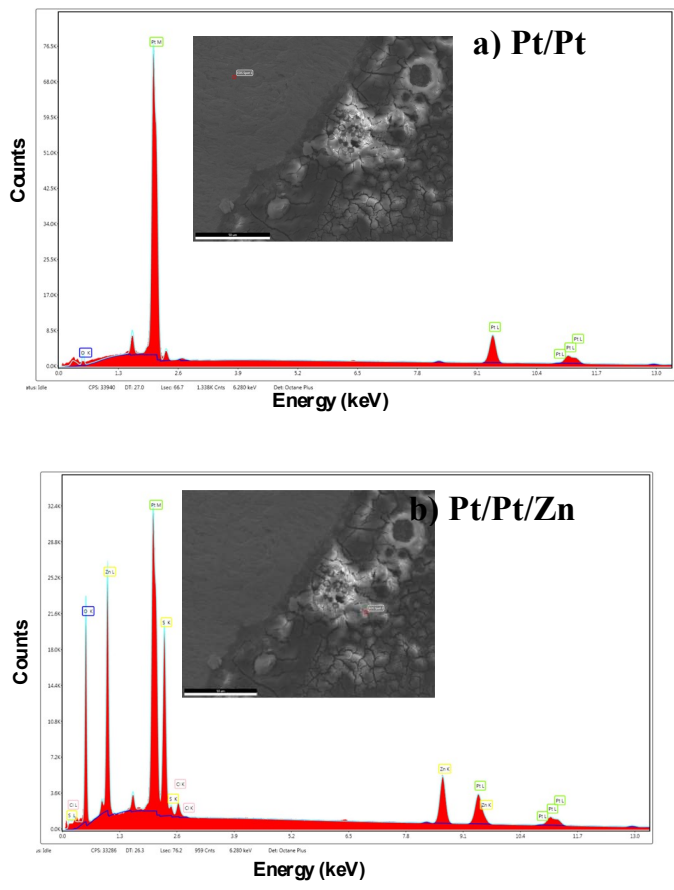

Figure 5. a) Micrograph SEM and EDX spectrums of Pt/Pt. b) Micrograph of SEM and EDX spectrums of $\mathrm{Pt} / \mathrm{Zn}$ after production of hydrogen.

Table 4. XRF Analysis of electrodes (wt $\%$ ).

\begin{tabular}{ccc}
\hline $\begin{array}{c}\text { Working } \\
\text { Electrodes }\end{array}$ & Pt & Zn \\
\hline $\mathrm{Pt} / \mathrm{Pt}$ & $99.99 \pm 0.01$ & - \\
$\mathrm{Pt} / \mathrm{Pt}-\mathrm{Zn}$ & $78.90 \pm 0.01$ & $21.10 \pm 0.01$ \\
\hline
\end{tabular}

\section{The contact angle (CA) measurements}

According to the contact angle measurements, the hydrophilicity of the $\mathrm{Zn}$ coated Pt electrode is increased. For this reason, the contact angle has decreased so; coating the surface of $\mathrm{Pt}$ with $\mathrm{Zn}$, increased the production of hydrogen (Fig. 6). 


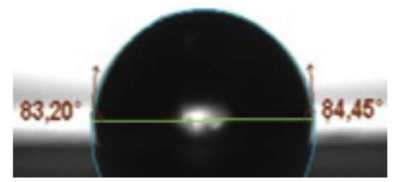

a) $\mathbf{P t} / \mathbf{P t}$

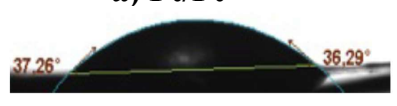

b) $\mathbf{P t} / \mathbf{P t} / \mathbf{Z n}$

Figure 6. Contact angle measurements a) $\mathrm{Pt} / \mathrm{Pt}, \mathrm{b}$ ) $\mathrm{Pt} / \mathrm{Pt} / \mathrm{Zn}$

\section{Conclusions}

According to the results obtained Pt/Pt-Zn electrode the efficiency for the producing of hydrogen is increased when efficiency is compared with $\mathrm{Pt} / \mathrm{Pt}$ electrode. At the same overvoltage, higher current and lower resistance occur in the $\mathrm{Pt} / \mathrm{Pt}-\mathrm{Zn}$ electrode. When the $\mathrm{Pt}-\mathrm{Zn}$ electrode is used as a cathode, the overvoltage in the electrolysis system falls and more hydrogen gas is produced. When the $\mathrm{Pt} / \mathrm{Pt}$ and $\mathrm{Pt} / \mathrm{Pt}-\mathrm{Zn}$ electrodes were compared, the production of hydrogen gas efficiency is increased by about $66.66 \%$. According to these results, when the Pt$\mathrm{Zn}$ electrode is used in the production of hydrogen gas, low resistance occurs in the electrolysis system during the formation of hydrogen gas and therefore less electrical energy will be consumed for the excessive voltages in the system. The advantage of working with platinum electrode is no corrosion in the system and therefore electrolyte is clean and more efficient during the electrolysis. Due to the catalytic activity of $\mathrm{Pt}$ and the superiority of the Pt catalyst the efficiency of hydrogen production is increased in a short period of experiment time.

\section{References}

[1] Song Y, Li J, Yang J. Graphene models and nano-scale characterization technologies for fuel cell vehicle electrodes. Renew Sustain Energy Rev 2015; 42: 66-77.

[2] Zerta M, Schmidt PR, Stiller C, Landinger H. Alternative World Energy Outlook (AWEO) and the role of hydrogen in a changing energy landscape. Int $\mathrm{J}$ Hydrogen Energy 2008; 33: 3021-25.

[3] Erbil M. Corrosion-Principles-Precautions, Ankara: Corrosion Soc Publication; 2012.

[4] Leckie HP, Uhling HH. Environmental Factors Affecting the Critical Potential for Pitting in 18-8 Stainless Steel. J Electrochem Soc 1996; 113: 1262-7.

[5] Ibrahim SM. Hydrogen storage in protonconductive perovskite-type oxides and their application. Korean J Chem Eng 2014; 31: 1792-7.

[6] Muradov NZ, Veziroglu TN. Green path from fossil-based to hydrogen economy: an overview of carbonneutral technologies. Int J Hydrogen Energy 2008; 33: 6804-39.

[7] Yadav JB, Park JW, Cho YJ, Joo OS. Intermediate hydroxide enforced electrodeposited platinum film for hydrogen evolution reaction. Int $\mathrm{J}$ Hydrogen Energy 2010; 35: 10067-72.

[8] Dutta S. Technology assessment of advanced electrolytic hydrogen production. Int J Hydrogen Energy 1990; 15: 379-86.

[9] Bockris JOM, Reddy AKN. Modern Electrochemistry 2, New York, Plenum Press; 1977.

[10] Soneyik VL, Jenkins D. Water Chemistry, New York, John Wiley and Sons; 1980.

[11] Mesrar F, Kacimi M, Liotta FL, Puleo F, Ziyad M. Hydrogen production on Ni loaded apatite-like oxide synthesized by dissolution precipitation of natural phosphate, Int J Hydrogen Energy 2017;42 19458-66.

[12] Evans GP. In Advances in Electrochemical Science and Engineering, vol.1 (Gerisher H, and Tobias 
CW. Eds.) pp.1-74, VCH, Germany, Verlag, Weinheim;1990.

[13] Torres C, Moreno B, Chinarro E, de Fraga Malfatti C. Nickel-polyaniline composite electrodes for hydrogen evolution reaction in alkaline media. Int $\mathrm{J}$ Hydrogen Energy 2017;42: 20410-19.

[14] Hernández-Ibáñez N, Lee JSM, Iniesta J, Leguey VM, Briggs ME, Cooper A I, Madrid E, Marken F. $\mathrm{pH}$ effects on molecular hydrogen storage in porous organic cages deposited onto platinum electrodes. J Electroanal Chem 2017. ISSN:1572-6657, https://doi.org/ 10.1016/ j.jelechem. 2017.07.009.

[15] Pletcher D, Li X. Prospects for alkaline zero gap water electrolysers for hydrogen production. Int $\mathrm{J}$ Hydrogen Energy 2011; 36: 15089-104.

[16] Santos DMF, Sequeira CAC, Figueiredo JL. Hydrogen production by alkaline water electrolysis. Quim. Nova 2013; 36: 1176-93.

[17] Rashid MM, Al Mesfer MK, Naseem H, Danish M. Hydrogen production by water electrolysis: a review of alkaline water electrolysis, PEM water electrolysis and high temperature water electrolysis. Int $\mathrm{J}$ Eng Adv Technol 2015; 4: 80-93.

[18] De Silva Munoz L, Bergel A, Feron D, Basseguy R. Hydrogen production by electrolysis of a phosphate solution on a stainless steel cathode. Int $\mathrm{J}$ Hydrogen Energy 2010; 35: 8561-68.

[19] Pourbaix M. Atlas of Electrochemical Aqueous Solutions, Vol. 1. (pp. 406-413). New York, USA, Pergamon Press; 1966. 